\title{
National Reactor Innovation Center NRC Early Site Permit Roadmap
}

\section{June 2021}

Alison Conner

George Griffith

Stephen Burdick 


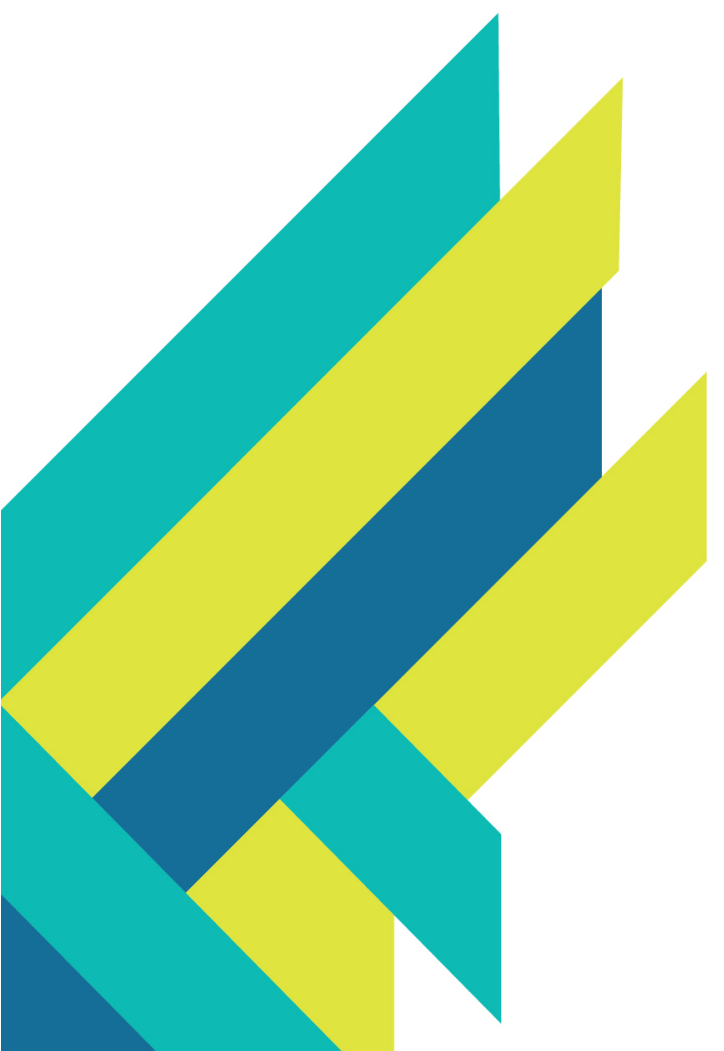

\section{DISCLAIMER}

This information was prepared as an account of work sponsored by an agency of the U.S.

Government. Neither the U.S. Government nor any agency thereof, nor any of their employees, makes any warranty, expressed or implied, or assumes any legal liability or responsibility for the accuracy, completeness, or usefulness, of any information, apparatus, product, or process disclosed, or represents that its use would not infringe privately owned rights. References herein to any specific commercial product, process, or service by trade name, trade mark, manufacturer, or otherwise, does not necessarily constitute or imply its endorsement, recommendation, or favoring by the U.S. Government or any agency thereof. The views and opinions of authors expressed herein do not necessarily state or reflect those of the U.S. Government or any agency thereof.

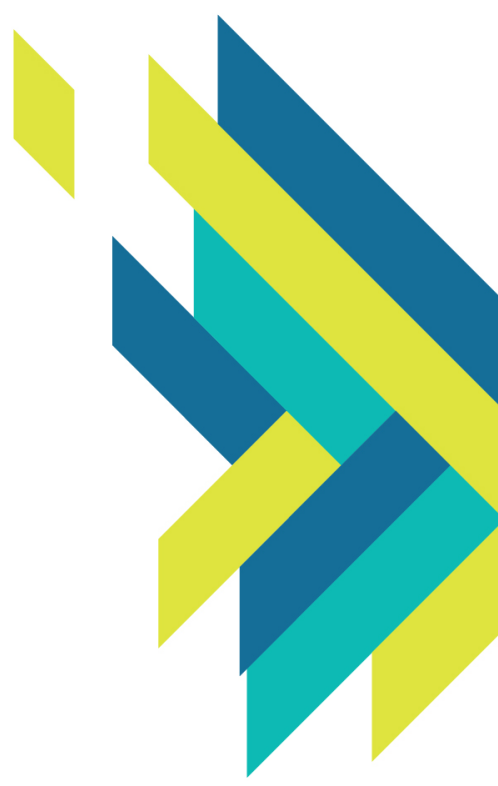




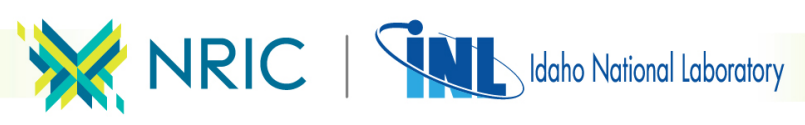

REVISION LOG

\begin{tabular}{|c|c|c|c|}
\hline $\begin{array}{c}\text { Revision } \\
\text { No. }\end{array}$ & Date & Affected Pages & Description \\
\hline 1 & $06 / 21$ & All & Incorporated external comments and updates \\
\hline & & & \\
\hline & & & \\
\hline & & & \\
\hline
\end{tabular}


Page intentionally left blank 


\section{SUMMARY}

The National Reactor Innovation Center (NRIC) is a U.S. Department of Energy (DOE) program led by Idaho National Laboratory (INL). NRIC will partner with the U.S. private sector, national laboratories, government agencies, and regulators to provide access to capabilities, facilities, and tools essential to the demonstration of new reactor technologies, and to address key barriers to success (INL 2020a).

NRIC accelerates the demonstration and deployment of advanced nuclear energy through its mission to inspire stakeholders and the public, empower innovators, and deliver successful outcomes through efficient coordination of partners and resources (INL 2020a). Some of these demonstration projects may be subject to DOE authorization, while other projects may require approval by the U.S. Nuclear Regulatory Commission (NRC) prior to construction and operation.

NRIC and INL are evaluating the process involved in pursuing one or more Early Site Permits (ESPs) from the NRC under 10 Code of Federal Regulations (CFR) Part 52 to help facilitate new reactor deployment at the INL Site. ESPs would allow early investment in licensing infrastructure in advance of reactor designs being ready to deploy. Through the ESPs, NRIC would help reduce the cost and time required to deploy demonstration reactors at the INL Site. This also would allow INL to bring its nuclear and siting experience to the ESP development process allowing for better and more efficient improvements and utilization of the Site. Preapproved ESPs at INL would also remove the uncertainty of NRC siting approvals from the demonstration project proponents, who may not be well positioned to complete the analyses in a timely manner.

The purpose of this NRIC ESP roadmap is to provide rigor and understanding needed for INL and DOE decision-makers to make data-informed decisions on pursuing NRC ESPs in support of future advanced reactor demonstrations at INL. The roadmap provides a structured method for addressing potential challenges and identifying options for resolution. The roadmap does not provide a recommendation on whether to actually pursue ESPs, as that decision will depend on a number of factors, such as funding, anticipated demonstration projects, and the status of parallel environmental reviews.

NRIC has identified the following steps as part of the strategy for obtaining ESPs to support advanced reactor development projects at INL:

1. The selected applicant (e.g., Battelle Energy Alliance (BEA), as the INL Prime Contractor, DOE, or a third party contracted by DOE) prepares and submits an ESP application to the NRC based on a generic Plant Parameter Envelope (PPE) and utilizing any relevant information from parallel environmental reviews at the INL or NRC. Further consideration of the appropriate applicant is necessary, including the regulatory obligations for the applicant.

2. NRC reviews the ESP application and issues ESPs to the applicant.

3. DOE considers future requests by demonstration project proponents to utilize the ESPs. This could be done in parallel or as part of the site use permit process.

4. The holder of the ESPs seeks NRC approval to transfer an ESP to the project proponent.

5. A demonstration project proponent proceeds with other NRC licensing activities to obtain approval for construction and operation of the project. 
Page intentionally left blank 


\section{CONTENTS}

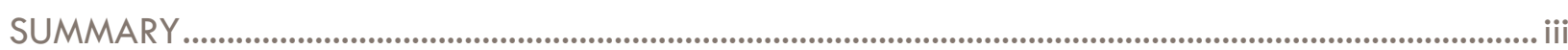

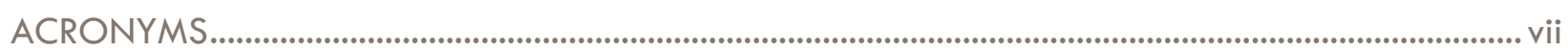

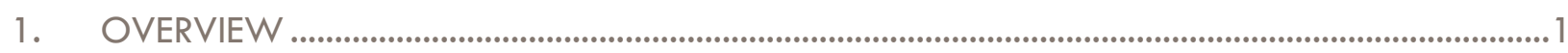

2. PROPOSED STRATEGY AND APPROACH FOR OBTAINING AND USING ESPS AT INL ...........3

2.1 Parallel Environmental Review Projects ................................................................................4

2.2 Plant Parameter Envelope and Number of Reactors/Sites ...............................................4

2.3 Alignment with NE-ID Site Use Permit Process ...............................................................................5

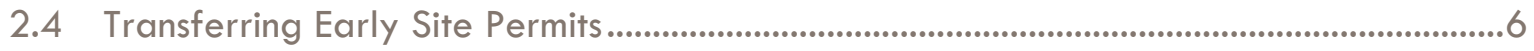

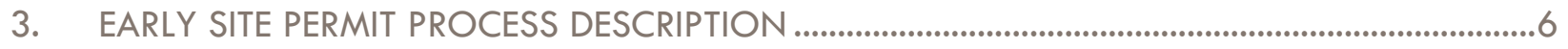

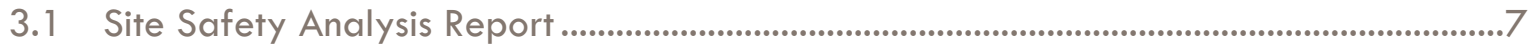

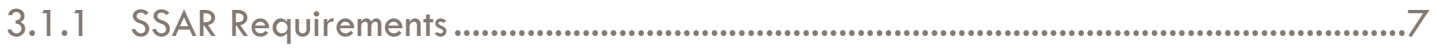

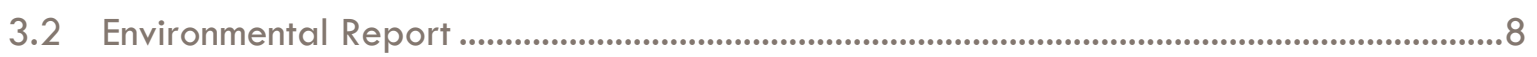

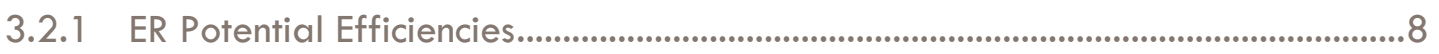

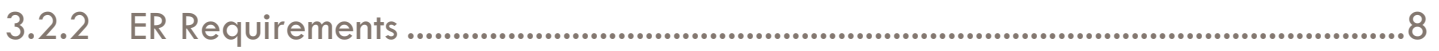

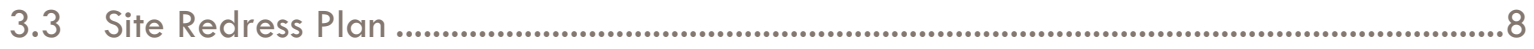

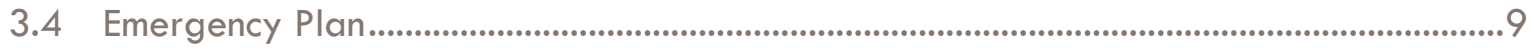

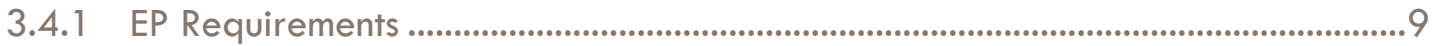

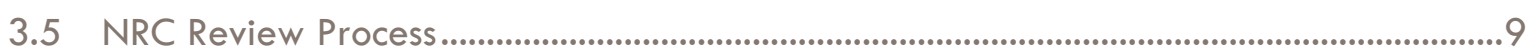

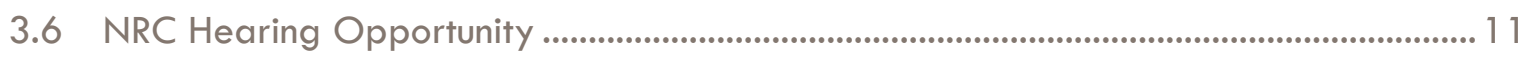

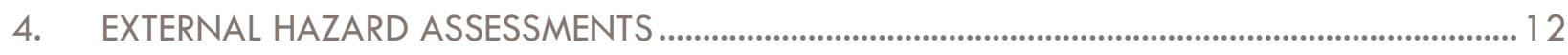

4.1 Senior Seismic Hazard Analysis Committee Level 3 Analysis............................................. 12

4.2 Probabilistic Volcanic Hazard Assessment ......................................................................... 13

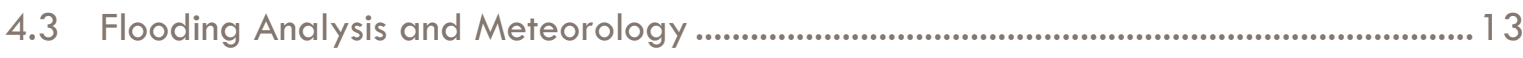

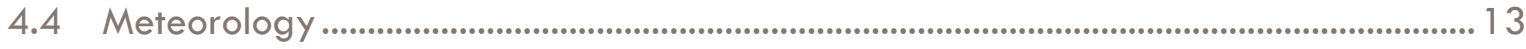

4.5 Man Made Hazards .................................................................................................................... 13

4.6 Light Detection and Ranging Analysis................................................................................... 14

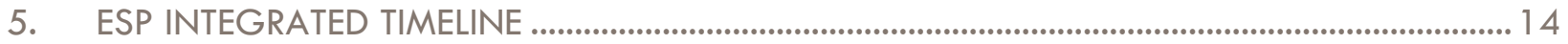

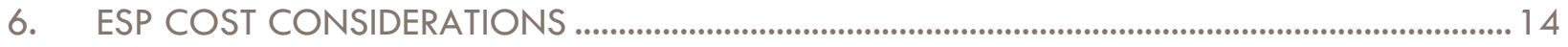

6.1 ESP Development Lessons Learned ............................................................................................ 14

6.2 NRC Historical ESP Application Review Costs ......................................................................... 15

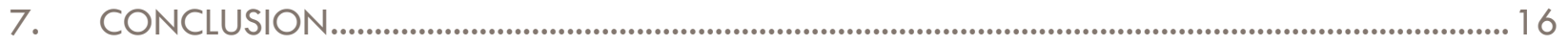

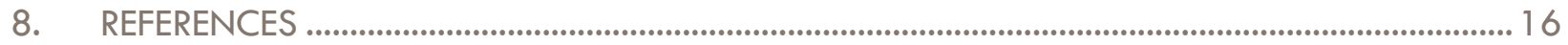

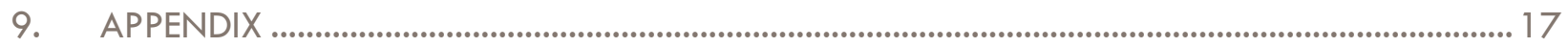




\section{FIGURES}

Figure 1. NRC ESP application review process.............................................................................. 11

\section{TABLES}

Table 1. NRC ESP estimated level of effort costs. .............................................................................. 15

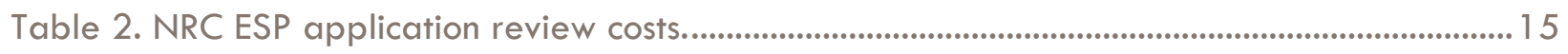




\section{ACRONYMS}

AR GEIS Advanced Reactor Generic Environmental Impact Statement

ASLB Atomic Safety and Licensing Board

ATR Advanced Test Reactor

BEA Battelle Energy Alliance, LLC

CFA Central Facilities Area

$\mathrm{COL}$ combined license

COLA combined license application

CFR Code of Federal Regulations

$\mathrm{CP} \quad$ construction permit

DOE Department of Energy

EP emergency plan

ER environmental report

ESP early site permit

INL Idaho National Laboratory

LWA limited work authorization

MFC Materials and Fuels Complex

NE Nuclear Energy

NE-ID Office of Nuclear Energy and the DOE Idaho Operations Office

NEI Nuclear Energy Institute

NEPA National Environmental Policy Act

NRC U.S. Nuclear Regulatory Commission

NRIC Nuclear Reactor Innovation Center

PPE plant parameter envelope

PSHA probabilistic seismic hazard analysis

RG regulatory guide

SECY NRC Commission paper

SER Safety Evaluation Report

SSAR site safety analysis report

SSHAC Senior Seismic Hazard Analysis Committee

TVA Tennessee Valley Authority 
Page intentionally left blank 


\section{National Reactor Innovation Center NRC Early Site Permit Roadmap}

\section{OVERVIEW}

The National Reactor Innovation Center (NRIC) is a U.S. Department of Energy (DOE) program led by Idaho National Laboratory (INL). NRIC will partner with the U.S. private sector, national laboratories, government agencies, and regulators to provide access to capabilities, facilities, and tools essential to the demonstration of new reactor technologies, and to address key barriers to success (INL 2020a).

NRIC accelerates the demonstration and deployment of advanced nuclear energy through its mission to inspire stakeholders and the public, empower innovators, and deliver successful outcomes through efficient coordination of partners and resources (INL 2020). As part of their plan to bridge the gap between R\&D and the commercial marketplace, and to help convert some of the nation's most promising advanced nuclear reactors into commercial applications, NRIC will build a demonstration resource network of publicly- and privately-owned sites, facilities, and capabilities suitable for performing key experiments, tests, or fabrications, and for hosting advanced reactor demonstrations throughout the United States. At INL, a preferred list of potential siting locations for demonstration and testing of advanced reactor technology has been evaluated and is available in INL/EXT-20-57821, "Evaluation of Sites for Advanced Reactor Demonstrations at Idaho National Laboratory." The list of preferred sites includes six previously developed and undeveloped outdoor locations and three existing buildings located at the Materials and Fuels Complex (MFC), Advanced Test Reactor (ATR) Complex, Central Facilities Area (CFA), and Idaho Nuclear Technology and Engineering Center (INL 2020b). Further review and approval will be necessary before final siting decisions can be made. Vendors will be able to install, test, and operate prototype reactor technology, then remove the prototype upon testing completion. In addition, undeveloped and previously developed outdoor sites, approximately 100 ac in size, have been identified as potential locations for construction and operation of fullscale reactor prototypes (INL 2020b). Some of these demonstration projects may be subject to DOE authorization, while other projects may require approval by the U.S. Nuclear Regulatory Commission (NRC) prior to construction and operation.

The NRC's Early Site Permit (ESP) process offered under Title 10 Code of Federal Regulations (CFR) Part 52, Subpart A, was promulgated by the NRC in 1989 to address some industry concerns with the former licensing process under 10 CFR Part 50. Previously, the licensing process required large expenditures of time and money by applicants well before key site-specific environmental, safety, and emergency planning issues could be resolved. The ESP process is meant to resolve these issues well in advance of a ready-to-build nuclear power facility and before substantial capital is invested in the construction of such a facility. An ESP can be obtained prior to selecting a particular reactor design using a Plant Parameter Envelope (PPE) approach in which the NRC reviews the project based on bounding assumptions about the reactor. An ESP is obtained through a separate process from the issuance of a construction permit (CP), an operating license, or a combined license (COL), which would need to be obtained before proceeding with construction and operation of any nuclear power plant (INL 2020b). As specified in 10 CFR $52.26(a)$, the NRC can issue an ESP for a period of 10-20 years.

PNNL-30992, "Advanced Nuclear Reactor Plant Parameter Envelope and Guidance," written by the Pacific Northwest National Laboratory (PNNL), describes a methodology for developing 
an advanced nuclear reactor PPE to facilitate environmental reviews of potential future advanced reactor demonstration projects at INL and elsewhere in the United States. It includes reactor vendor responses to NRIC questionnaires, input from INL staff, independent assessments by subject matter experts, and a review of regulatory requirements a vendor would have to meet during construction and operation. This report presents the compiled PPE for a surrogate plant derived from these inputs, lists documentation supporting the PPE, and provides recommendations for its use in an environmental review (PNNL 2021).

The national deployment of advanced reactors will require not only technical innovations, but innovations in the regulatory processes for siting and construction. To facilitate DOE's plans for reactor demonstration and deployment at INL, NRIC and INL are evaluating the process involved in pursuing one or more ESPs to help facilitate new reactor deployment at the INL Site. NRIC has identified an approach using the NRC's ESP process to pre-approve a site or sites at INL. As envisioned, the selected applicant (e.g., Battelle Energy Alliance (BEA), DOE, or a third party contracted by DOE) could apply for and receive an ESP or ESPs from the NRC approving the site(s) for future construction and operation of a demonstration reactor. A single application likely could result in multiple ESPs for multiple sites at INL. The ESPs would be based on one or more PPEs, allowing NRC generic review of the sites without knowing the specific reactor designs.

Once DOE determines that a particular demonstration project requiring a future NRC license is appropriate for the INL Site (perhaps through or in parallel with the existing site use permit process), then an ESP could be transferred through an NRC licensing process to the demonstration project proponent. That project proponent would then be responsible for obtaining the necessary additional NRC approvals to proceed with construction and operation of the demonstration project, but that process should be expedited and more efficient given the siting approvals represented by the ESP. Ongoing efforts by the NRC to prepare an Advanced Reactor Generic Environmental Impact Statement (AR GEIS) and any future decisions by DOE to prepare any environmental reviews which address advanced reactors on the INL Site could also facilitate pursuit of the ESPs.

This ESP strategy should result in significant benefits to DOE, INL, and demonstration project proponents. ESPs would allow early investment in licensing infrastructure in advance of reactor designs being ready to deploy. Through the ESPs, NRIC would help reduce the cost and time required to deploy demonstration reactors at the INL Site. This would also allow INL to bring its nuclear and siting experience to the ESP development process allowing for better and more efficient improvements and utilization of the Site. Preapproved ESPs at INL would also remove the uncertainty of NRC siting approvals from the demonstration project proponents who may not be well positioned to complete the analyses in a timely manner.

The purpose of this NRIC ESP roadmap is to provide rigor and understanding needed for INL and DOE decision-makers to make data-informed decisions on pursuing NRC ESPs in support of future advanced reactor demonstrations at INL. The roadmap provides a structured method for addressing potential challenges and identifying options for resolution. The roadmap does not provide a recommendation on whether to actually pursue ESPs, as that decision will depend on a number of factors, such as funding, anticipated demonstration projects, and the status of parallel environmental reviews.

Section 2 below provides a more detailed description of the overall envisioned strategy and approach for obtaining and using ESPs at INL for reactor demonstration projects. Section 3 addresses the regulatory and licensing process for obtaining ESPs from the NRC. Section 4 discusses some important considerations for external hazard assessments that will need to be 
addressed for the ESPs. Section 5 provides a high-level timeline for obtaining the ESPs. Finally, Section 6 discusses costs related to obtaining the ESPs.

\section{PROPOSED STRATEGY AND APPROACH FOR OBTAINING AND USING ESPS AT INL}

An ESP would provide early NRC approval of a location for a demonstration project. This could provide substantial benefit to demonstration project proponents by shortening the NRC licensing process to achieve approval for construction and operation of an NRC-licensed reactor. This would benefit DOE/INL/NRIC by supporting their missions of enabling such demonstration projects.

A preliminary question for an ESP application for the INL Site is: who would be the applicant? Although further discussion is necessary, multiple options are available. Under NRC regulations either DOE or BEA reasonably could apply for and become the holder of any ESP issued by the NRC through this effort. The NRC's regulations allow any "person"a to submit an application for an ESP as long as they meet the various technical qualifications required to be an ESP holder and other high-level requirements that apply to all applications. Using BEA as the ESP applicant in its role as the Prime Contractor for INL, and under DOE oversight, may provide more flexibility to use the resources and capabilities within BEA. This also would align closely with NRIC's mission to facilitate demonstration projects. An applicant or holder of an ESP, however, would be required to comply with a limited set of relevant NRC regulations. Whether BEA or DOE is the applicant, it would be necessary to further consider these implications and any potential conflicts with other work performed by INL for the NRC. Nonetheless, both BEA and DOE appear to present options as applicants consistent with the NRC regulations. Additionally, DOE may be able to contract with another qualified third-party entity to be the applicant. For example, DOE had contracted with a third party to obtain the NRC license for the Idaho Spent Fuel Facility. Further consideration of the appropriate applicant is necessary.

The overall strategy for the ESPs would proceed as follows:

1. The selected applicant (e.g., BEA, DOE, or a third party contracted by DOE) prepares and submits an ESP application to the NRC based on a generic PPE and utilizing any relevant information from parallel environmental reviews at the INL or NRC.

2. NRC reviews the ESP application and issues ESPs to the applicant. This review process is discussed in detail in Section 3.

3. DOE considers future requests by demonstration project proponents to utilize the ESPs. This could be done in parallel or as part of the existing site use permit process.

4. The holder of the ESPs seeks NRC approval to transfer an ESP to the project proponent.

5. A demonstration project proponent proceeds with other NRC licensing activities to obtain approval for construction and operation of the project.

a As defined in 10 CFR 50.2, a "person" includes "any individual, corporation, partnership, firm, association, trust, estate, public or private institution, group, government agency other than the Commission or the Department, except that the Department shall be considered a person to the extent that its facilities are subject to the licensing and related regulatory authority of the Commission pursuant to section 202 of the Energy Reorganization Act of 1974 ...." 
Additional details on some of the key considerations for this strategy are discussed below.

\subsection{Parallel Environmental Review Projects}

Pursuit of ESPs for future demonstration projects at the INL Site could be facilitated by ongoing environmental review processes at INL and the NRC. First, DOE is considering preparation of environmental reviews which would consider expansion of some capabilities at the INL Site. Although the scope of those environmental reviews has not been determined, it potentially could consider advanced reactor demonstration, testing, and operations, or related activities.

Because the environmental analyses for these potential demonstration projects would be nearly identical to the analyses that would be required by the NRC to issue an ESP, this ESP effort could utilize any DOE environmental reviews for the environmental input to the NRC in an ESP application, providing efficiency and cost savings. There may be some differences given DOE may evaluate the environmental impacts slightly different than the NRC does, or there may be new information between the two projects, but NRIC anticipates potential efficiencies here.

Second, the NRC is preparing an Advanced Reactor Generic Environmental Impact Statement (AR GEIS), which is expected to evaluate and make findings on certain environmental issues generically for all projects that fall within specified parameters. The NRC staff completed an exploratory process in February 2020 to consider the viability of developing the AR GEIS for the construction and operation of advanced reactors. The NRC staff concluded that an AR GEIS is viable, and it planned to use a technology-neutral PPE approach for small reactors (preliminarily up to $30 \mathrm{MWth}$ ) (NRC 2020a). In September 2020, the NRC Commission approved proceeding with the AR GEIS, but with further consideration of the size of reactors covered and with rulemaking to codify the generic findings (NRC 2020b). Depending on the timing of these AR GEIS activities, they could potentially greatly reduce the number and types of environmental issues that would need to be addressed in an ESP application. The NRC's activities should provide substantial time and cost savings if the timing supports an ESP project at INL.

\subsection{Plant Parameter Envelope and Number of Reactors/Sites}

Another preliminary question is how many reactors and sites within the INL Site should be covered by the ESP application. As noted above, DOE already is considering preparation of environmental reviews which could provide DOE National Environmental Policy Act (NEPA) review of advanced reactor projects. The activities discussed above could be based on multiple PPEs: one for microreactors and one for larger advanced reactors. This ESP project could cover those same reactors, including the same proposed sites (limited to those located outside existing facilities) and PPEs. Therefore, the scope of those DOE environmental reviews combined with consideration of expected demonstration projects could be used to determine the number of reactors and sites covered by an ESP application.

As described in Nuclear Energy Institute (NEI)-10-01, the use of an ESP that is based on a PPE allows the deferral of the technology selection until the applicant submits the COL application (COLA) to the NRC. Nonetheless, a PPE must bound all of the potential technologies that may be selected, and so some narrowing of technology may be advisable within the PPE. This deferral of the technology decision is key to maintaining commercial flexibility and lowering overall commercial risk. A two-step licensing process that includes a technology-neutral, site-specific ESP, followed by a technology-specific COLA, provides an optimum approach to balancing licensing and financial risks by enabling:

- Early resolution of site-specific issues 
- Deferral of technology selection

- Technology selection concurrent with commercial agreement (INL 2020b).

As one example, the Tennessee Valley Authority (TVA) recently used the PPE approach in its application to the NRC for an ESP for the Clinch River site. Although a reactor design was not specified, TVA identified bounding parameters for a surrogate, water-cooled nuclear plant, which NRC used to evaluate the suitability of the site for the building and operation of a new nuclear plant falling within those parameters. Prior to TVA's building and operating a plant at the site, NRC would need to review and approve an additional application from TVA (either a COL or a CP) that includes a specific reactor design. The NRC has issued earlier ESPs based on PPEs as well.

This PPE approach at INL matching the environmental review activities under consideration would ensure consistency with the demonstration reactor plans for the INL Site and the use of overlapping information would ensure efficiency and cost savings. It is expected that a single ESP application could be submitted and reviewed and result in multiple ESPs: one for each reactor demonstration project/site. In this regard, the NRC regulations at 10 CFR 52.8(a) state that "[a]n applicant for a license under this part may combine in its application several applications for different kinds of licenses under the regulations of this chapter." The NRC likely will need to consider the interactions between the various demonstration projects (as well as existing activities on the Site) and a single application would facilitate that review. The result of this approach would be both DOE and NRC approvals of the demonstration reactor sites.

\subsection{Alignment with NE-ID Site Use Permit Process}

The Office of Nuclear Energy (NE) and the DOE Idaho Operations Office (NE-ID) has implemented procedure, 08.OD.02 - "Siting Request Review," so that it may grant permission for commercial use of portions of the INL Site. Companies interested in locating commercial activities at INL must submit a formal request and be fully vetted by NE-ID. These entities must be approved to conduct activities through the issuance of site use permits, which provide such approved entities a grant to site at INL.

Utilization of the NE-ID site use permit process provides a high-level strategy for conducting due diligence reviews of siting requests for commercial activities on the INL Site. To enter into a site use permit, a company must demonstrate, in its siting request, an acceptable level of feasibility in the areas of technology development, licensing, financial capability, communication strategy (including local Tribal engagement), export control, and environmental aspects (NEPA, waste disposition, etc.). Depending on the level of technical maturity associated with the proposed activity, NE-ID may elect to first enter into a memorandum of understanding agreement with the company to support further development of the proposed activity and to further consider the feasibility of the activities the company has proposed to site at INL. Subject to this feasibility evaluation, the company and NE may ultimately negotiate a site use permit.

DOE may choose to utilize the NE-ID site use permit process to vet and determine if a demonstration project requiring a future NRC license is appropriate for the INL Site and whether to transfer an ESP to a demonstration project proponent. The process for considering what entity should receive an ESP would need to address many of the same issues considered in the site use permit process. 


\subsection{Transferring Early Site Permits}

Once DOE or BEA holds an ESP for the INL Site, then it can later seek NRC approval to transfer the ESP to a demonstration project proponent once DOE determines that proponent should receive it. The NRC regulations at 10 CFR 52.28 explicitly allow such a transfer with NRC approval, stating: "An application to transfer an early site permit will be processed under 10 CFR 50.80." Section 50.80(a) in turn states that no ESP "or any right thereunder, shall be transferred, assigned, or in any manner disposed of, either voluntarily or involuntarily, directly or indirectly, through transfer of control of the license to any person, unless the Commission gives its consent in writing." Therefore, an ESP may be transferred with NRC consent.

Section 50.80 specifies a transfer process with an application that demonstrates that the recipient of the ESP satisfies the administrative and technical qualifications, which applied to the original applicant. In particular, regarding the content of an application for transfer, 10 CFR 50.80 (b)(1)(ii) states: "For an early site permit under part 52 of this chapter, as much of the information described in $\S \S 52.16$ and 52.17 of this chapter with respect to the identity and technical qualifications of the proposed transferee as would be required by those sections if the application were for an initial license." Section 52.16 identifies the general administrative information which must be provided in an application, while Section 52.17 identifies the required technical information.

The NRC has transferred an ESP before under 10 CFR 52.28. System Energy Resources, Inc. was the permit holder for the Grand Gulf ESP No. ESP-002 for a site adjacent to the Grand Gulf Nuclear Station in Claiborne County, Mississippi. Due to a company reorganization, Entergy requested that the NRC consent to the transfer of the Grand Gulf ESP to a new limited liability company, System Energy Resource, LLC. After the transfer, the ultimate parent company (Entergy Corporation) would remain the same, but a new intermediate company would be created. The NRC reviewed the request against the above requirements and approved it. Entergy had submitted the application on September 27, 2012 and received approval on May 3, 2013, a period of about 7 months.

It is not unusual for transfers of other NRC licenses under 10 CFR 50.80 to take about 6-12 months, although the review for these requests is much simpler than for a full licensing application such as an ESP application. However, the reviews typically require a docketing period, requests for additional information from the NRC, and preparation of a safety evaluation. These transfers also provide an opportunity for members of the public to request a hearing, although these requests are not frequent and can only challenge a narrow scope of information submitted to satisfy NRC requirements for transfers.

Once an ESP is transferred, then it becomes the responsibility of the new holder to satisfy all applicable NRC requirements related to that ESP or subsequent activities to rely upon the ESP as part of later applications. There should not be any residual obligations by the former ESP holder to the NRC.

\section{EARLY SITE PERMIT PROCESS DESCRIPTION}

The ESP process offered under 10 CFR Part 52, Subpart A, was promulgated by the NRC in 1989 to address industry concerns with the licensing process under 10 CFR Part 50. The Part 50 licensing process required large expenditures of time and money by applicants well before key site-specific environmental, safety, and emergency planning issues could be resolved. As envisioned, the ESP process is meant to resolve these issues well in advance of a decision to build 
a nuclear power facility and before substantial capital is invested in the construction of a new nuclear facility (INL 2020b).

The ESP application is required to provide design information pertaining to structures, systems, and components along with site-specific parameters (such as meteorology, demographics, and hydrology) and address site safety, environmental protection, and emergency planning. Although an ESP applicant does not need to specify a particular nuclear plant design, as in CP applications, it does need to provide sufficient surrogate-design information (developed to bound nuclear plant designs that are being considered by the applicant) so that the NRC can make a determination on the acceptability of the site and the environmental impacts and determine whether designs bounded by the surrogate-design information provided by the applicant can be qualified for the proposed site (INL 2020b).

In addition to administrative information on the applicant, including general information required by 10 CFR 50.33(a) through (d) and (i), the ESP application must include the following major elements:

- Site Safety Analysis Report (SSAR)

- Environmental Report (ER)

- Site Redress Plan (if needed)

- Emergency Plan.

Once an ESP application is submitted, the NRC staff performs a thorough review of the safety, environmental, and other necessary topics. That review includes opportunities for public meetings and consideration by the NRC's Advisory Committee on Reactor Safeguards. The NRC's review culminates with a mandatory, uncontested hearing overseen by the NRC Commission or a delegated Atomic Safety and Licensing Board (ASLB), which is a panel of three NRC administrative judges. A parallel contested hearing opportunity also is provided that could potentially impact schedule.

The contents of an ESP application, the NRC's review process, and the hearing opportunity are discussed in more detail below.

\subsection{Site Safety Analysis Report}

The SSAR is similar in format to a COL Final Safety Analysis Report. The SSAR content includes detailed site-specific characteristics and the potential reactor facility information that applies to the issuance of an ESP (INL 2020b).

\subsubsection{SSAR Requirements}

The specific regulatory bases and associated guidance documents for the SSAR include:

Atomic Energy Act

- NRC Regulations, 10 CFR Parts 50,52 and 100

- NRC Regulatory Guide (RG) 1.70, "Standard Format and Content of Safety Analysis Reports for Nuclear Power Plants"

- NUREG-0800, "Standard Review Plan for the Review of Safety Analysis Reports for Nuclear Power Plants"

- NRC RG 1.206, Revision 1, "Applications for Nuclear Power Plants" 
- NRC RG 1.233, "Guidance for a Technology-Inclusive, Risk-Informed, and Performance-Based Methodology to Inform the Licensing Basis and Content of Applications for Licenses, Certifications, and Approvals for Non-Light Water Reactors"

- NRC RG 4.7, "General Site Suitability Criteria for Nuclear Power Stations"

- NEl guidance document NEI-10-01, "Industry Guideline for Developing a Plant Parameter Envelope in Support of an Early Site Permit," Revision 1 (INL 2020b).

\subsection{Environmentall Report}

The ER is a report required by 10 CFR 51.50 (b) to be included in each application for an ESP. The ER contains a description of the proposed action and a statement of its purposes, characterization of the affected environment, and analyses of the potential environmental impacts associated with the proposed action. The applicant's ER is a source of information used by the NRC in preparing an EIS. The EIS is a detailed written statement prepared by the NRC to meet the requirements of Section 102(2)(C) of the National Environmental Policy Act of 1969, as amended (NEPA) (INL 2020b).

\subsubsection{ER Potential Efficiencies}

As noted above, DOE is considering preparation of environmental reviews for advanced reactors. It is anticipated that much of the information required to prepare the ER for the ESP application could come from those efforts if they are undertaken. Additionally, the AR GEIS under development by the NRC likewise could simplify the amount and types of information necessary in an ER for an ESP. This should provide efficiency and cost savings and ensure environmental reviews are consistent.

\subsubsection{ER Requirements}

The specific regulatory bases and associated guidance documents for the ER include:

- NEPA

- NRC Regulations in 10 CFR Parts 51 and 52

- NRC RG 4.2, "Preparation of Environmental Reports for Nuclear Power Stations"

- NUREG-1555, "Environmental Standard Review Plans"

- State environmental statutes, as applicable (INL 2020b).

\subsection{Site Redress Plan}

The NRC regulations at 10 CFR 50.10 identify certain "construction" activities, which require NRC approval before commencing. Section 50.10 also identifies certain activities not considered construction requiring NRC approval, including site exploration, site preparation, fencing, excavation, support buildings, etc. If an ESP applicant wishes to be able to perform the NRClicensed construction activities at a site before issuance of a COL, then the applicant must identify and describe the activities and receive a Limited Work Authorization (LWA) from the NRC. An LWA request could be submitted with an ESP application. That LWA request must propose a plan for redress of the site in the event that the activities are performed and either construction is abandoned or the LWA revoked.

Because DOE/INL would be preparing the ESP application with the intent of transferring it to a private company and full construction plans would not be known at the time of the ESP application, an LWA likely would not provide any benefit as part of an ESP application. 
Therefore, a site redress plan would not be required with the ESP application. If a demonstration project proponent desired to complete NRC-licensed construction activities prior to receiving a $\mathrm{COL}$ or $\mathrm{CP}$, then it could consider filing a separate LWA request with the NRC.

\subsection{Emergency Plan}

10 CFR 50.47(a)(1) requires that an applicant provide adequate protective measures in the event of a radiological emergency. Emergency planning activities must include the development of adequate plans for the plume exposure pathway emergency planning zone and ingestion pathway emergency planning zone.

Per 10 CFR 52.17(b)(2) and (b)(3), an ESP applicant has two options in developing the Emergency Plan (EP). The applicant can choose to address major features, such as the exact size and configuration of the emergency planning zones, for review and approval by the NRC, in consultation with the Federal Emergency Management Agency per 10 CFR 52.17(b)(2)(i), or deliver a complete and integrated EP for review and approval by the NRC, in consultation with the Federal Emergency Management Agency per 10 CFR 52.17(b)(2)(ii).

EPs submitted under paragraph (b)(2)(ii) of 10 CFR 52.17 must include the proposed inspections, tests, and analyses that the holder of a COL referencing the ESP shall perform, and the acceptance criteria that are necessary and sufficient to provide reasonable assurance that, if the inspections, tests, and analyses are performed and the acceptance criteria met, the facility has been constructed and will be operated in conformity with the EPs, the provisions of the Act, and the NRC's rules and regulations. Major features of an EP submitted under paragraph (b)(2)(i) of 10 CFR 52.17 may include proposed inspections, tests, analyses, and acceptance criteria.

Given the strategy of the ESP project to use a PPE and not knowing who the ultimate ESP holder will be and who will be responsible for an EP, NRIC concludes that submitting only the major features EP allowed under 10 CFR 52.17(b)(2)(i) appears to be the appropriate approach at this time. Development of a complete and integrated EP also may be challenging without understanding the reactor design and the commercial plans of the unknown demonstration project proponent. This topic also should be discussed further with the NRC to establish an appropriate approach for the EP to cover the multiple sites contemplated by the above strategy.

\subsubsection{EP Requirements}

The specific regulatory bases and associated guidance documents for the emergency planning information include:

- NRC Regulations in 10 CFR Parts 50 and 52

- NUREG-0396, "Planning Basis for the Development of State and Local Government Radiological Emergency Response Plans in Support of Light Water Nuclear Power Plants"

- NUREG-0654, "Criteria for Preparation and Evaluation of Radiological Emergency Response Plans and Preparedness in Support of Nuclear Power Plants"

- NRC RG 1.101, "Emergency Planning and Preparedness for Nuclear Power Plants"

- NRC RG 1.183, "Alternate Radiological Source Terms for Evaluating Design Basis Accidents at Nuclear Power Reactors" (INL 2020b).

\subsection{NRC Review Process}

The NRC ESP application review process is illustrated in the figure below (INL 2020b). Although not shown on the figure, the applicant would engage in extensive pre-application 
interactions with the NRC staff about the project and any unique aspects. This should provide significant later efficiencies and understanding, particularly with the unique ESP application envisioned here. For TVA, the pre-application activities took place over a two-year period and is documented in letters and other correspondence relating to possible licensing, project regulatory framework, and construction of SMR modules at the CRN site. This documentation can be accessed on the NRC website at https://www.nrc.gov/reactors/new-reactors/smr/clinch-river/preapp.html.

The applicant would engage with other stakeholders, as well. For example, NEl guidance document NEI-10-07, "Industry Guideline for Effective Pre-Application Interactions with Agencies Other Than NRC During the Early Site Permit Process," Revision 1, provides a framework to guide interactions between prospective applicants with agencies other than NRC (e.g., federal, state, and local) that become involved in the licensing and permitting processes.

Once the application is submitted, the NRC staff performs an acceptance review to ensure the application provides sufficient information to proceed with the review. Once accepted, the review process generally splits into an environmental review and a site safety review. The environmental review process will proceed with a typical EIS preparation process, including scoping meetings, issuance of requests for additional information, preparation of a draft ElS, public meetings and comments on the draft EIS, and finally issuance of a final EIS. The safety review proceeds with issuance of requests for additional information, an advanced Safety Evaluation Report (SER), review by the Advisory Committee on Reactor Safeguards, and finally issuance of a final SER. As part of the ESP application review, the NRC also may engage in certain types of inspection/audit activities, such as review of the proposed and alternative sites, quality assurance, etc.

Following completion of the final EIS and final SER, the NRC staff submits a SECY (Commission paper) report to the Commission outlining the review and recommending issuance of the ESP. The Commission then conducts or delegates to the ASLB to conduct a "mandatory hearing." This mandatory hearing process proceeds somewhat similar to other NRC hearings with questions and responses, written testimony, and an in-person hearing with sworn witnesses. This hearing is uncontested because the only parties are the applicant and the NRC staff who both support issuance of the ESP at this point of the review. The mandatory hearing culminates with a written decision from the Commission or ASLB. Assuming the hearing is favorable, then the NRC will proceed with issuance of an ESP. 


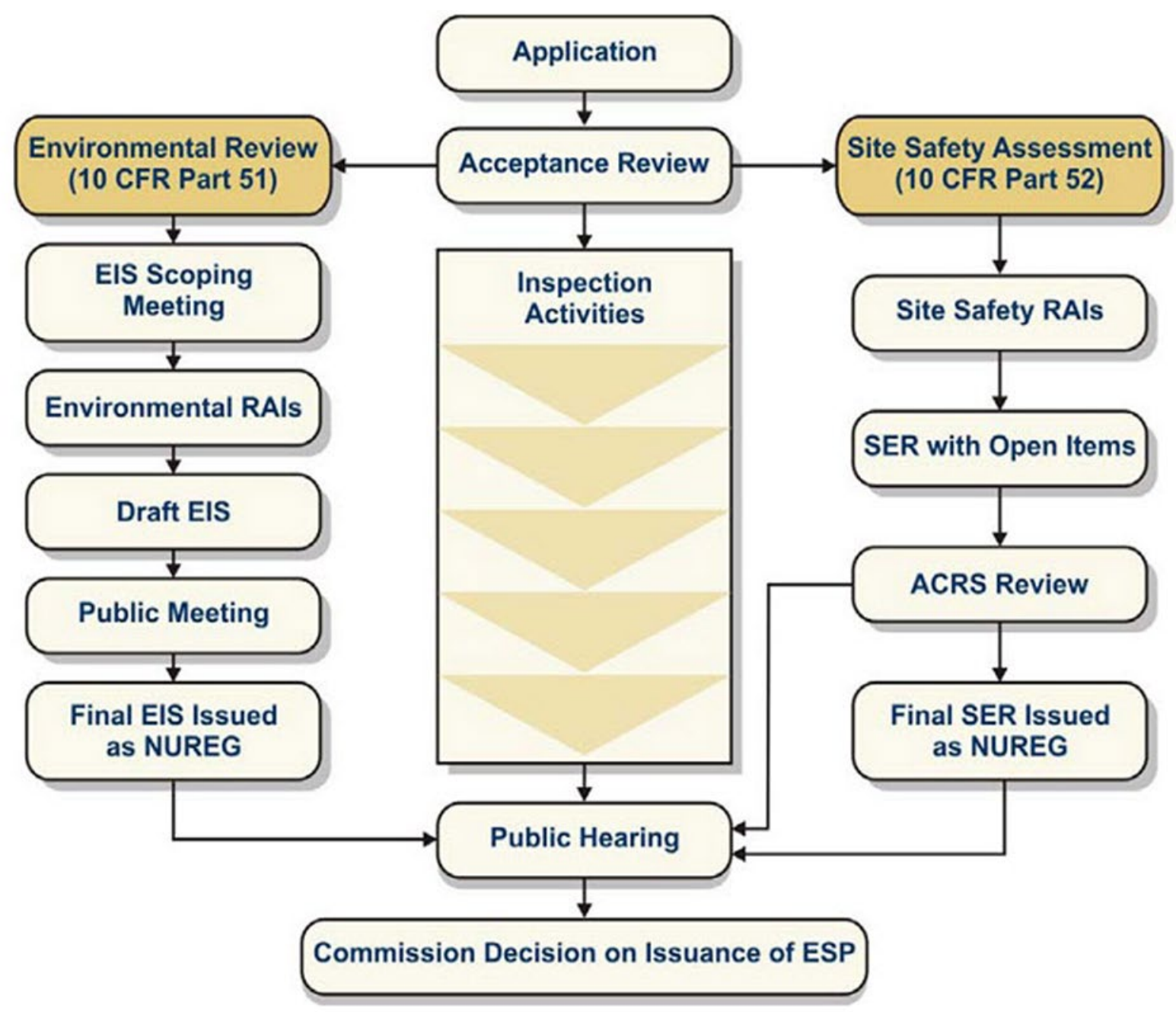

Figure 1. NRC ESP application review process.

\subsection{NRC Hearing Opportunity}

Aside from the NRC review process discussed above, the NRC also provides an opportunity for members of the public or other interested stakeholders to request a hearing to challenge an ESP application. The NRC typically issues an opportunity to request a hearing in conjunction with or shortly after the issuance of a notice that an application has completed the acceptance review.

The notice of an opportunity to request a hearing typically will provide petitioners with 60 days to request a hearing. That notice also details the stringent requirements to obtain a hearing, which are further set forth in 10 CFR 2.309. Those include the hearing request must be timely, must demonstrate the legal standing of the petitioner to participate in a hearing, and must identify at least one appropriate challenge, or "contention," contesting the application.

If a petitioner submits a hearing request, then the Commission typically establishes an ASLB to rule on the request. The applicant and the NRC staff will have the opportunity to respond to a hearing request. The ASLB then typically holds an oral argument by legal counsel to obtain further input on the hearing requests. The ASLB ultimately will rule on whether any request should be 
granted. If the ASLB rejects a hearing request, then a petitioner may appeal to the Commission (and later to the Federal Appellate Courts). There also may be opportunities for late hearing requests based on any new and materially different information that becomes available throughout the NRC's review process.

If the ASLB grants a hearing request, then the applicant and NRC staff have the opportunity to appeal it under some circumstances. Assuming the approval of the hearing request holds, then the parties enter a more formal hearing process with disclosure obligations related to the topics of the hearing, and there may be further activities to try to reject or expand the scope of the hearing. These activities proceed in parallel with the NRC staff's review of the application. The hearing process typically proceeds on environmental topics once the NRC issues the final EIS and on safety topics once the NRC issues an SER (sometimes on the advanced SER). The standard hearing process is typically an informal process with written testimony, dispositive motions, and proposed questions for the ASLB to ask. The process culminates with an in-person hearing with sworn witnesses and questioning by the ASLB. Following post-hearing pleadings, the ASLB will issue a decision on the hearing. This may be appealed to the Commission and then to the Federal Appellate Courts.

Because the hearing process does not proceed until after the NRC issues its SER and/or EIS, which are late in the review process, this contested hearing process has the potential to delay issuance of an ESP. The exact impact is difficult to predict because it is possible there will be no hearing requests or those requests will be rejected in parallel with the NRC staff's review of the application. However, it typically takes about 1 year from the issuance of the SER and/or EIS until the ASLB issues a decision on a hearing.

\section{EXTERNAL HAZARD ASSESSMENTS}

The following sections describe INL sitewide efforts that will provide input to the ESP application and may become key inputs to determining whether the pursuit of an ESP will be of value to future reactor demonstration vendors at INL. The outcomes of these efforts should be integrated into the timeline and ESP application completion.

\subsection{Senior Seismic Hazard Analysis Committee Level 3 Analysis}

INL last completed a probabilistic seismic hazard analysis (PSHA) in 1996 that, with updated computations in 2000, currently supports the seismic safety basis of existing INL nuclear facilities classified as Seismic Design Category 3 and above. The initial 1996 PSHA was not conducted under the Senior Seismic Hazard Analysis Committee (SSHAC) framework since it predates the development of NRC's SSHAC guidance, thus it cannot be used to support the design of new nuclear facilities. INL recently completed a SSHAC Level 1 study (INL 2019a) at three INL sites (ATR, MFC, and NRF), which identified key seismic hazard issues and provided a starting point for the INL Sitewide SSHAC Level 3 study. The tentatively planned completion date for the SSHAC Level 3 analysis is February 2022 (INL 2020b).

The key outcomes of the SSHAC Level 3 analysis that are relevant to the advanced reactor siting study and future siting studies include the following:

- Establishing the INL PSHA

- Identifying the general INL Site upgrade that is a long lead item in reactor deployment

- Completing an NRC-approved seismic evaluation

- Creating Nuclear Quality Assurance (NQA)-1 data from diverse geologic data 
- Enabling lower-level updates for follow up analysis (INL 2020b).

\subsection{Probabilistic Volcanic Hazard Assessment}

As part of ongoing INL operations, INL is evaluating how to address volcanic hazards across the Site. INL has an intrinsic need to remain current on volcanic hazards. INL has many activities that require assessment of volcanic hazard including ATR operations, MFC operations, storage licenses, 10-year safety updates, VTR deployment, DOD sponsored reactors and NRC-licensed reactors.

The NRC is examining the guidance for volcanic hazard evaluations and has an updated Regulatory Guide prepared. This process is being watched closely by DOE and may influence expectations for the INL site. The updating of methodology will create a more robust and useful safety evaluation.

The updated evaluation is based on the Senior Seismic Hazard Analysis Committee (SSHAC) process being implemented by INL for the probabilistic seismic hazard assessment. The SSHAC process utilizes expert reviews and consensus to create high (NQA-1) results from a broad variety of input data at different quality levels and input assumptions. The volcanic analysis will result in a probabilistic volcanic hazard assessment that will be suitable for NRC licensing.

INL has created a project execution plan and is seeking approval to go forward with the evaluation. The results would be available to support the ESP and incoming nuclear projects.

\subsection{Flooding Analysis and Meteorology}

An analysis of flooding hazards is part of evaluating any potential reactor site. Flooding hazards are calculated based on previous conditions and the worst potential conditions. Hurricanes, storms, dam breaks, ice dams and tsunamis are all evaluated, as necessary. The work can be largely done using existing data.

\subsection{Meteorology}

The effects of weather covering all atmospheric conditions at the site are evaluated. High winds, tornadoes, hurricanes, and snow are all evaluated. The data is taken from historic analysis except for the need for contemporary wind and weather conditions are expected for 2 years at QL-1 levels. This data is used in evaluating radiation transport and doses during accidents. The data is required to evaluate the license safety conditions.

INL evaluated deploying new wind towers to support the data collection needs. Each tower and data collection effort will cost an estimated \$300K-\$325K (INL 2020c). The ESP applicant would need to coordinate with the NRC to determine whether new meteorological towers are needed to support an ESP application or whether existing data is sufficient to address the NRC's requirements.

\subsection{Man Made Hazards}

The site should account for local manmade hazards able to affect the site. These issues can be related to any facilities that could have an influence on the long-term safe shutdown of the plant or ability to control the plant. Chemical or nuclear facilities would be specific examples of manmade hazards near a reactor. The effects of INL operations on the reactor site and the reactor site effects on INL operations need to be considered. The particular analysis depends on local facilities. The analysis is currently being discussed because of the complex relationship, 
including who is a member of the public, between the DOE operations and potential nuclear plant operations.

\subsection{Light Detection and Ranging Analysis}

INL recently performed a sitewide Light Detection and Ranging survey of the INL Site. The work was performed to support ongoing INL safety evaluations and as a site improvement. The analysis is performed by taking a very detailed elevation survey using lasers from an overhead aircraft. The measurements can show building outlines, power poles, surface faulting, historic cultural artifacts and the potential for water and volcanic flooding.

The survey performed for INL covered areas considerably beyond the physical boundaries of the Site. This allows potential flooding paths and seismic faults that may affect the area to be surveyed. This survey will be valuable for flooding analysis and volcanic evaluations.

\section{ESP INTEGRATED TIMELINE}

Appendix A contains an integrated timeline of the activities necessary to achieve an NRC ESP.

\section{ESP COST CONSIDERATIONS}

\subsection{ESP Development Lessons Learned}

Due to the business sensitivity of cost information, actual costs to prepare previous ESP applications are not available for distribution.

Based on conversations with those involved with prior ESP application preparations and the lessons learned assessment report that NRC issued in April 2021 for the Clinch River Nuclear Site ESP application review (NRC 2021), below is a list of lessons learned shared regarding the ESP development process and keys to success:

- Engage with the NRC as early as possible to enable open communications and quick resolution of potential key issues that might come up.

- Recommend having a single point of contact with licensing experience during the preapplication phase that can prepare documented responses to the NRC.

- Get documented agreement early on between applicant and NRC on what the scope should be and what is needed to meet the requirements.

- Establish standard communication meetings at all levels of the organization to enable easy escalation and resolution of potential issues.

- Identify a core team that will lead the development of the ESP application and will be engaged throughout the process.

- Recommend having a dedicated team to manage review and approvals of applicant outputs.

- Maintain the core development team through the NRC review to ensure expedient responses to requests for information.

- Validate that data collection and calibration tools and methods meet NRC requirements, specifically for long lead data collection efforts.

- Although actual ESP development costs are proprietary, the total development cost is comparable to the total cost that NRC charged to complete the application reviews. 
If DOE and INL decision-makers decide to continue with investigation of this ESP roadmap, then more specific cost information should be obtained from contractors who are experienced with preparing applications to the NRC.

\subsection{NRC Historical ESP Application Review Costs}

To enhance stakeholder awareness of costs associated with licensing activities, the NRC published, on their website, staff resource estimates for the new reactor business line that include license amendments, COLs, ESPs, and design certifications. The estimated hours in Table 1 represent low level of effort, high level of effort, and average estimates of NRC professional staff hours and contractor costs for the six ESPs completed as of April 2020. These estimates include project management and engineering review activities and costs related to the SER and EIS, but do not include pre-application interactions requested by the applicant.

Table 1. NRC ESP estimated level of effort costs.

\begin{tabular}{|c|c|c|c|c|c|c|c|c|}
\hline \multicolumn{3}{|c|}{ NRC Staff Hours* } & \multicolumn{3}{c|}{ Contractor Cost (M) } & \multicolumn{3}{c|}{ Total Estimated Cost (M) } \\
\hline $\begin{array}{c}\text { Low } \\
\text { Level of } \\
\text { Effort }\end{array}$ & $\begin{array}{c}\text { High } \\
\text { Level of } \\
\text { Effort }\end{array}$ & Average & $\begin{array}{c}\text { Low } \\
\text { Level of } \\
\text { Effort }\end{array}$ & $\begin{array}{c}\text { High } \\
\text { Level of } \\
\text { Effort }\end{array}$ & Average & $\begin{array}{c}\text { Low } \\
\text { Level of } \\
\text { Effort }\end{array}$ & $\begin{array}{c}\text { High } \\
\text { Level of } \\
\text { Effort }\end{array}$ & Average \\
\hline 14,626 & 64,940 & 29,104 & $\$ 1.87$ & $\$ 5.11$ & $\$ 2.76$ & $\$ 5.94$ & $\$ 23.16$ & $\$ 10.85$ \\
\hline
\end{tabular}

* For current NRC labor rates, refer to the most recent Fee Rule. For FY19, the rate is $\$ 278 /$ hour. Staff hours and contractor costs are based on completed application reviews. Costs include the safety evaluation report and environmental impact statement but do not include pre-application interactions requested by the applicant.

In the $31^{\text {st }}$ monthly report from the NRC to the Committee on Environment and Public Works and the Clean Air and Nuclear Safety Subcommittee, the NRC reported total fees billed for each design certification, COL, and ESP application reviewed since 2007. The information provided by the NRC reflected updates through June 2019 (Letter from Svinicki to The Honorable John A. Barrasso):

Table 2. NRC ESP application review costs.

\begin{tabular}{|l|l|l|c|}
\hline Project Name & $\begin{array}{c}\text { Date Application } \\
\text { Was Filed }\end{array}$ & ESP Issued Date & $\begin{array}{c}\text { Total Fees } \\
\text { Billed for Each } \\
\text { Review }\end{array}$ \\
\hline Clinton ESP & September 25, 2003 & March 15, 2007 & $\$ 5,186,587$ \\
\hline Grand Gulf ESP & October 21, 2003 & April 05, 2007 & $\$ 5,352,875$ \\
\hline North Anna ESP & September 25, 2003 & November 27, 2007 & $\$ 8,579,177$ \\
\hline Vogtle ESP & August 15, 2006 & August 26, 2009 & $\$ 11,680,269$ \\
\hline PSEG ESP & May 25, 2010 & May 05, 2016 & $\$ 17,917,093$ \\
\hline Clinch River ESP & May 12, 2016 & December 19, 2019 & $\$ 14,342,723 *$ \\
\hline
\end{tabular}

* Included in the April 2021 NRC lessons-learned assessment report (NRC 2021) was a summary of total expenditures for the Clinch River Nuclear Site ESP application review. It concluded that 38,973 NRC staff hours were required and approximately $\$ 3,469,256$ in contract dollars. Using the professional staff-hour rate of $\$ 279 /$ hour, as stated in 10 CFR 170.20 , dated September 18, 2020, this would result in $\$ 10,873,467$ in Staff fees. The total estimated cost was calculated to be $\$ 14,342,723$ $(\$ 3,469,256+\$ 10,873,467)$. 
Based on this information and the efficiencies that can be gained that were discussed above, a conservative rough order of magnitude cost estimate for the NRC review of a DOE or BEA ESP application is $\$ 10,757,042-\$ 25,099,765(-25 \%$ to $+75 \%$ of $\$ 14,342,723)$.

\section{CONCLUSION}

The purpose of this NRIC ESP roadmap is to provide rigor and understanding needed for INL and DOE decision-makers to make data-informed decisions on pursuing NRC ESPs in support of future advanced reactor demonstrations at INL. The roadmap provides a structured method for addressing potential challenges and identifying options for resolution. The roadmap also should provide useful information related to ESPs for advanced reactor demonstrations at other DOE sites.

As discussed above, NRIC has formulated a high-level strategy in which BEA or DOE could obtain ESPs from the NRC based on generic reactor parameters and consistent with other environmental reviews. DOE could later determine whether specific reactor demonstration project proponents should receive the ESPs. If so, then those ESPs could be transferred to those proponents with NRC approval. Although discussion with the NRC on some key issues and further investigation of costs are advisable, this strategy should provide substantial benefits to the timing and costs of demonstration projects at the INL Site.

\section{REFERENCES}

10 CFR Part 50, U.S. Code of Federal Regulations, Title 10, "Energy," Part 50, "Domestic Licensing of Production and Utilization Facilities," Appendix A, "General Design Criteria for Nuclear Power Plants."

10 CFR Part 51, U.S. Code of Federal Regulations, Title 10, "Energy," Part 51, "Environmental Protection Regulations for Domestic Licensing and Related Regulatory Functions."

10 CFR Part 52, U.S. Code of Federal Regulations, Title 10, "Energy," Part 52, "Licenses, Certifications, and Approvals for Nuclear Power Plants."

INL, 2020a, "NRIC Strategy and Program Execution Plan." INL/MIS-20-5971 1, Rev. 2.

INL, 2020b, "Summary Overview of Content Guidance for Early Site Permit Applications." INL/EXT-20-59137, Rev. 0.

INL, 2020b. "Evaluation of Sites for Advanced Reactor Demonstrations at Idaho National Laboratory." INL/EXT-20-57821, Rev. 0.

INL, 2020c, "NRIC Met Tower Recommendations," INL/EXT-20-59823, Rev. 0.

NEI-10-01, "Industry Guideline for Developing a Plant Parameter Envelope in Support of an Early Site Permit," Revision 1.

NEI-10-07, "Industry Guideline for Effective Pre-Application Interactions with Agencies Other Than NRC During the Early Site Permit Process," Revision 1.

NRC, 2020a, SECY-20-0020, "Results of Exploratory Process for Developing a Generic Environmental Impact Statement for the Construction and Operation of Advanced Nuclear Reactors."

NRC, 2020b, SRM-SECY-20-0020, "Staff Requirements - SECY-20-0020 - Results of Exploratory Process for Developing a Generic Environmental Impact Statement for the Construction and Operation of Advanced Nuclear Reactors." 
NRC, 2021, ML19190A078, "Clinch River nuclear Site ESPA Review - Best Practices and Lessons Learned."

NRC letter from Kristine L. Svinicki to The Honorable John A. Barrasso, August 16, 2019, and enclosure, "Status Report on the Licensing Activities and Regulatory Duties of the U.S. Nuclear Regulatory Commission, for the Reporting Period through June 2019."

NRC Regulatory Guide 1.101, "Emergency Planning and Preparedness for Nuclear Power Plants."

NRC Regulatory Guide 1.183, "Alternate Radiological Source Terms for Evaluating Design Basis Accidents at Nuclear Power Reactors."

NRC Regulatory Guide 1.206, Revision 1, "Applications for Nuclear Power Plants."

NRC Regulatory Guide 1.233, "Guidance for a Technology-Inclusive, Risk-Informed, and Performance-Based Methodology to Inform the Licensing Basis and Content of Applications for Licenses, Certifications, and Approvals for Non-Light Water Reactors."

NRC Regulatory Guide 1.70, "Standard Format and Content of Safety Analysis Reports for Nuclear Power Plants."

NRC Regulatory Guide 4.2, "Preparation of Environmental Reports for Nuclear Power Stations.

NRC Regulatory Guide 4.7, "General Site Suitability Criteria for Nuclear Power Stations."

NUREG-0800, "Standard Review Plan for the Review of Safety Analysis Reports for Nuclear Power Plants."

NUREG-1555, "Environmental Standard Review Plan: Standard Review Plans for Environmental Reviews for Nuclear Power Plants."

NUREG-0396, "Planning Basis for the Development of State and Local Government Radiological Emergency Response Plans in Support of Light Water Nuclear Power Plants."

NUREG-0654, "Criteria for Preparation and Evaluation of Radiological Emergency Response Plans and Preparedness in Support of Nuclear Power Plants."

PNNL, 2021, "Advanced Nuclear Reactor Plant Parameter Envelope and Guidance." NRIC-2 1 ENG-0001; PNNL-30992.

\section{APPENDIX}

Appendix A, INL ESP Integrated Timeline 
Page intentionally left blank 


\section{Appendix A INL ESP Integrated Timeline}


Page intentionally left blank 


\section{Appendix A \\ INL ESP Integrated Timeline}

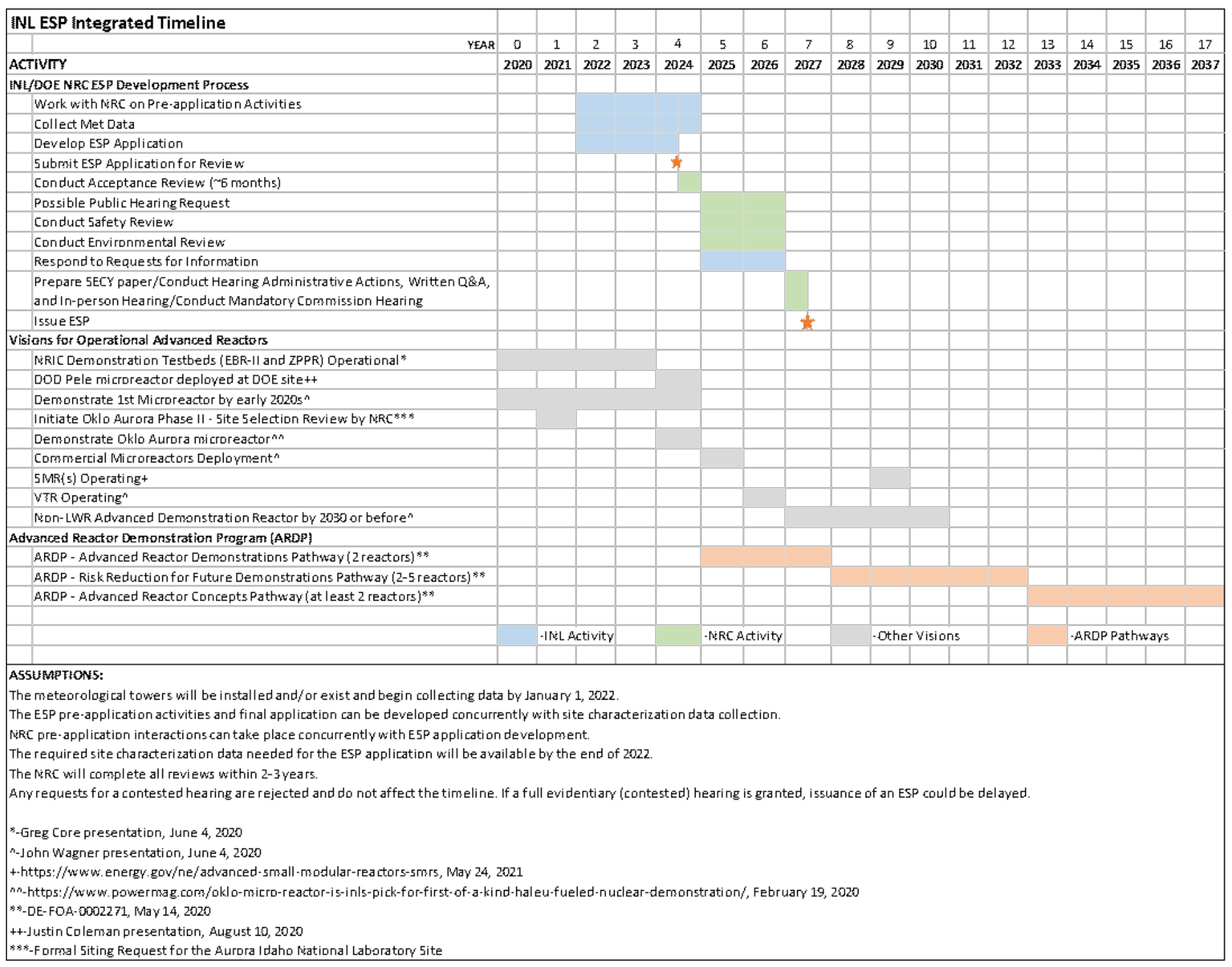

